\title{
Chemical Composition and Acaricidal Effects of Essential Oils Extracted from Ligustrum japonicum against Acaridae and Pyroglyphid Mites
}

\author{
Hoi-Seon Lee*
}

Received: 31 December 2014 / Accepted: 13 January 2015 / Published Online: 30 September 2015

(C) The Korean Society for Applied Biological Chemistry 2015

\begin{abstract}
The composition of the essential oil of Ligustrum japonicum leaves was determined by GC-MS analysis. The major constituents of $L$. japonicum leaf oil were germacrene D (40.50\%), $\alpha$-pinene $(13.63 \%),(-)-\beta$-elemene $(6.42 \%), \quad \beta$-caryophyllene $(5.73 \%)$, and $\delta$-cadinene $(5.47 \%)$. The acaricidal activities of $L$. japonicum oil were evaluated against acaridae and pyroglyphid mites. In the fumigant bioassay, the $\mathrm{LD}_{50}$ values of $L$. japonicum oil were $16.48,12.38$, and $15.63 \mu \mathrm{g} / \mathrm{cm}^{3}$ against Tyrophagus putrescentiae, Dermatophagoides farinae, and D. pteronyssinus, respectively. In the contact bioassay, the $\mathrm{LD}_{50}$ values of $L$. japonicum oil were $8.02,5.02$, and $7.67 \mu \mathrm{g} / \mathrm{cm}^{2}$ against $T$. putrescentiae, D. farinae, and $D$. pteronyssinus, respectively.
\end{abstract}

Keywords acaricidal activity $\cdot$ Ligustrum japonicum $\cdot$ pyroglyphid mites $\cdot$ Tyrophagus putrescentiae

The significance of acaridae mite, Tyrophagus putrescentiae (storage mite), and pyroglyphid mites, Dermatophagoides farinae and D. pteronyssinus, with regard to allergic diseases is known in the world (Arlian, 1989). These mites are the most serious factors of allergens, causing asthma and atopic dermatitis (Yang and Lee, 2012). Acaridae and pyroglyphid mites have been known to be the hygienic pests for storage products and apartment dusts and are important allergen factors within stored grains and apartment

H.-S. Lee

Department of Bioenvironmental Chemistry and Institute of Agricultural Science \& Technology, College of Agriculture \& Life Science, Chonbuk National University, Jeonju 561-756, Republic of Korea

*Corresponding author (H.-S. Lee: hoiseon@jbnu.ac.kr)

This is an Open Access article distributed under the terms of the Creative Commons Attribution Non-Commercial License (http://creativecommons. org/licenses/by-nc/3.0/) which permits unrestricted non-commercial use, distribution, and reproduction in any medium, provided the original work is properly cited. environments in the humid areas (Azima et al., 2011). Stored grains, wall-to-wall carpeting, and space heating in the lifestyle of humans have promoted favorable environmental conditions for the growth of acaridae and pyroglyphid mites (Yang et al., 2013). The population of acaridae and pyroglyphid mites has preferentially been controlled by synthetic acaricide such as $N, N$-diethyl- $m$ toluamide (DEET). However, repeated attempts of synthetic acaricides have resulted in residual toxicity and resistance (Jeon and Lee, 2011). These problems have pointed the need for the development of effective acaricides against acaridae and pyroglyphid mites (Yang et al., 2014).

Ligustrum japonicum Thunb. (Oleaceae) is known as Wax Privet originating from Korea and Japan. This tree has a thick covering of green leaves throughout the whole year, making it an evergreen plant. The L. japonicum flowers are followed by black fruits in June. The fruit is an oval drupe ripening in purple-black color with a glaucous bloom in December. Previous studies have indicated that $L$. japonicum flowers are abundant in active materials responsible for aldose reductase inhibition (Papoti et al., 2011), antibacterial (Doh, 2010), and antioxidant (Papoti et al., 2011) effects. It contains $\alpha$-terpinolene, hotrienol, 2-methoxyphenol, benzenemethanol, and tricosane (Lim et al., 2008). However, there are a few studies on the acaricidal effects of the L. japonicumderived materials against acaridae and pyroglyphid mites. To analyze the composition of the essential oils obtained from $L$. japonicum leaves, the volatile constituents of $L$. japonicum oil were identified by GC-MS to assess the acaricidal effects.

Sample preparation and GC-MS analysis. L. japonicum leaves were purchased from Youngchon local market (Korea) and extracted by steam distillation. The essential oil obtained from the extract (yield $0.18 \%$ ) was dried over $\mathrm{Na}_{2} \mathrm{SO}_{4}$ and concentrated by evaporation (EYELA NAJ-100, Japan) at $31^{\circ} \mathrm{C}$. L. japonicum oil was analyzed by GC-MS (5973 IV, Agilent, USA). DB-5 column ( $30 \mathrm{~m} \times 0.25 \mathrm{~mm}$, Folsom, CA) was used for GC-MS analysis, and the column conditions used are as follows: injector temperature, $210^{\circ} \mathrm{C}$; DB-5 column temperature, isothermal at $51^{\circ} \mathrm{C}$ for $16 \mathrm{~min}$, then increased to $203^{\circ} \mathrm{C}$ at $1.7^{\circ} \mathrm{C} / \mathrm{min}$ and maintained at this 
temperature for $16 \mathrm{~min}$; an ion source temperature, $231^{\circ} \mathrm{C}$. Helium was injected at a rate of $0.7 \mathrm{~mL} / \mathrm{min}$. The effluent of the DB-5 column was used in the mass spectrometer. Spectra were measured in the electron ionization mode at $71 \mathrm{eV}$. The mass was analyzed in the $\mathrm{m} / \mathrm{z}$ range between 10 and 425 , and the sector mass analyzer was set in the scan range $50-800 \mathrm{amu}$ for $2 \mathrm{~s}$. The chemical composition was determined by comparing the retention time, and mass data was obtained when the standard chemical was analyzed using the DB-5 column. When the standard chemical was unavailable, the identification of the compounds derived from L. japonicum oil was measured by comparing The Wiley Registry of Mass Spectral Data (7th ed.) and Adams library (Adams, 2007).

Acaridae and pyroglyphid mites. The cultures of $D$. farinae, $D$. pteronyssinus, and T. putrescentiae were kept in an incubator. These mites were reared in the containers $\left(25 \times 25 \times 20 \mathrm{~cm}^{3}\right)$ containing diet (dried yeast and fry feed no. 1) at $26 \pm 2{ }^{\circ} \mathrm{C}$ and $69 \pm 4 \%$ relative humidity $(\mathrm{RH})$ in dark area. The fry feed consisted of cellulose $(4.0 \%)$, calcium $(1.8 \%)$, protein $(44.0 \%)$, phosphate $(2.0 \%)$, lipids $(3.0 \%)$, and others $(40.2 \%)$. To synchronize the mite developmental cycles, acaridae and pyroglyphid mites were placed in dishes $\left(80 \times 20 \mathrm{~mm}^{2}\right)$ and allowed to lay eggs for $50 \mathrm{~h}$. The laid eggs of acaridae and pyroglyphid mites were checked for the stages using a microscope until adults died. The fumigant method was modified by the bioassay described by Lee et al. (2009). The acaricidal activities of $L$. japonicum oil were bioassayed using the fumigant bioassay against acaridae and pyroglyphid mites. Different quantities $\left(20-10 \mu \mathrm{g} / \mathrm{cm}^{3}\right)$ of $L$. japonicum oil were dissolved in acetone $(25 \mu \mathrm{L})$ and applied to disks $(0.8 \times 0.1$ $\mathrm{cm}^{2}$ ). Pure acetone was used as the negative control. The treated paper disk was dried in a hood for $10 \mathrm{~min}$ and then placed at the top of a microtube $(2 \mathrm{~mL})$. Thirty acaridae and pyroglyphid mites were inoculated in microtubes, which were sealed using the cap with the paper disk. Biological comparisons and processing of the samples were determined under the same conditions as acaridae and pyroglyphid mites for $24 \mathrm{~h}$. The acaricidal effects of the samples were measured using the contact bioassay against acaridae and pyroglyphid mites by the acaricidal bioassay modified as described by Jeon et al. (2012). Six concentrations (10-3 $\left.\mu \mathrm{g} / \mathrm{cm}^{2}\right)$ of $L$. japonicum oil were liquefied in acetone $(50 \mu \mathrm{L})$. The sample was injected in a petri dish $\left(35 \times 10 \mathrm{~mm}^{2}\right)$ and dried for $10 \mathrm{~min}$. Thirty acaridae and pyroglyphid mites were inoculated in petri dishes, and the lid was closed. The dishes were maintained at $25 \pm 11^{\circ} \mathrm{C}$ and $70 \% \mathrm{RH}$ for $24 \mathrm{~h}$. Mite mortalities were measured using a microscope after $24 \mathrm{~h}$. All the treatments were replicated twice, and $\mathrm{LD}_{50}$ was measured using SAS software (SAS Institute, 1990). The relative toxicity was calculated based on DEET LD $_{50} /$ sample $\mathrm{LD}_{50}$ (Jeon et al., 2012).

L. japonicum oil was measured by GC-MS, and retention time, retention index, and mass spectra of each constituent were compared to those reported in the literature (Hendriks et al., 2005; Lim et al., 2008). The chemical composition of the essential oil is listed in Table 1. Relative composition (\%) of the constituents derived from L. japonicum oil was germacrene D (40.50\%), $\alpha$ -
Table 1 GC-MS analyses of volatile constituents from L. japonicum oil

\begin{tabular}{clc}
\hline Retention time & \multicolumn{1}{c}{ Constituents } & Relative composition (\%) \\
\hline 4.946 & $\alpha$-Pinene & 13.63 \\
5.746 & $\beta$-Pinene & 2.34 \\
5.921 & Myrcene & 0.88 \\
6.688 & $( \pm)$-Limonene & 2.91 \\
9.220 & $(-)$-Borneol & 0.31 \\
9.612 & $\alpha$-Terpineol & 0.34 \\
12.518 & $(+)$-Cycloisosativene & 1.55 \\
12.616 & $\alpha$-Copaene & 4.33 \\
12.814 & $(-)$ - $\beta$-Elemene & 6.42 \\
13.295 & $\beta$-Caryophyllene & 5.73 \\
13.773 & $\alpha$-Humulene & 4.46 \\
14.171 & Germacrene D & 40.50 \\
14.338 & $\alpha$-Muurolene & 2.76 \\
14.552 & $\alpha$-Amorphene & 0.68 \\
14.642 & $\delta$-Cadinene & 5.47 \\
16.195 & Muurolol & 2.89 \\
16.359 & $\alpha$-Cadinol & 3.66 \\
\hline
\end{tabular}

pinene (13.63\%), (-)- $\beta$-elemene (6.42\%), $\beta$-caryophyllene $(5.73 \%)$, $\delta$-cadinene $(5.47 \%), \alpha$-humulene $(4.46 \%), \alpha$-copaene $(4.33 \%), \alpha$ cadinol (3.66\%), $( \pm)$-limonene $(2.91 \%)$, muurolol $(2.89 \%), \alpha-$ muurolene (2.76\%), $\beta$-pinene $(2.34 \%),(+)$-cycloisosativene $(1.55 \%)$, myrcene $(0.88 \%)$, $\alpha$-amorphene $(0.68 \%)$, $\alpha$-terpineol $(0.34 \%)$, and (-)-borneol $(0.31 \%)$. The constituents of L. japonicum oil were grouped as alkenes ( $\beta$-caryophyllene, $\alpha$-copaene, $(+)$ cycloisosativene, $(-)$ - $\beta$-elemene, germacrene $\mathrm{D}, \alpha$-humulene, $( \pm)$ limonene, myrcene, $\alpha$-pinene, and $\beta$-pinene), alcohol ((-)-borneol, $\alpha$-cadinol, muurolol, and $\alpha$-terpineol), and naphthalene ( $\alpha$ amorphene, $\alpha$-muurolene, and $\delta$-cadinene). According to Lim et al. (2008), the volatile components of essential oil extracted from L. japonicum flowers were $\alpha$-terpinolene (4.36\%), hotrienol (9.21\%), 2-methoxyphenol (5.01\%), benzenemethanol (6.72\%), tricosane $(8.05 \%)$, and 3,7,11-trimethyl-2,6,10-dodecatrien-1-ol $(5.20 \%)$. In the current and previous studies, the volatile constituents of the essential oils derived from L. japonicum flowers and leaves were affected by the harvest time, storage period, intraspecific variability, handling method, and experimental methods, indicating the optimum extraction method and plant parts (flowers, leaves, and fruits) (Hendriks et al., 2005).

Essential oil was extracted from L. japonicum leaves in $0.18 \%$ yield $(\mathrm{v} / \mathrm{w})$. To measure the acaricidal effects, the acaricidal potential of L. japonicum oil was determined by the contact and fumigant bioassays against $D$. farinae, $D$. pteronyssinus, and $T$. putrescentiae. Compared to the $\mathrm{LD}_{50}$ values of DEET, the acaricidal potential of L. japonicum oil $(12.38,15.63$, and 16.48 $\mu \mathrm{g} / \mathrm{cm}^{3}$ ) proved to be more toxic than that of DEET $(36.50,34.23$, and $30.31 \mu \mathrm{g} / \mathrm{cm}^{3}$ ) against $D$. farinae, D. pteronyssinus, and $T$. putrescentiae in fumigant bioassay, respectively (Table 2). In the contact bioassay, the acaricidal activity of $L$. japonicum oil (5.02, 7.67 , and $8.02 \mu \mathrm{g} / \mathrm{cm}^{2}$ ) was more potent than that of DEET (19.64, 14.12 , and $14.15 \mu \mathrm{g} / \mathrm{cm}^{2}$ ) against $D$. farinae, D. pteronyssinus, 
Table 2 Acaricidal effects of L. japonicum oil and a synthetic acaricide against acaridae and pyroglyphid mites ${ }^{\mathrm{a}}$

\begin{tabular}{|c|c|c|c|c|c|}
\hline Samples & Bioassay & Mite species & $\mathrm{LD}_{50}$ & $95 \% \mathrm{CL}$ & $\mathrm{RT}^{\mathrm{b}}$ \\
\hline \multirow{6}{*}{ L. japonicum oil } & \multirow{3}{*}{$\begin{array}{l}\text { Fumigant } \\
\left(\mu \mathrm{g} / \mathrm{cm}^{3}\right)\end{array}$} & D. farinae & 12.38 & $11.39-13.37$ & 2.95 \\
\hline & & D. pteronyssinus & 15.63 & $14.64-16.62$ & 2.19 \\
\hline & & T. putrescentiae & 16.48 & $15.45-17.38$ & 1.84 \\
\hline & \multirow{3}{*}{$\begin{array}{l}\text { Contact } \\
\left(\mu \mathrm{g} / \mathrm{cm}^{2}\right)\end{array}$} & D. farinae & 5.02 & $4.78-5.26$ & 3.91 \\
\hline & & D. pteronyssinus & 7.67 & $6.92-8.42$ & 1.84 \\
\hline & & T. putrescentiae & 8.02 & $7.14-8.81$ & 1.76 \\
\hline \multirow{6}{*}{ DEET } & \multirow{3}{*}{$\begin{array}{l}\text { Fumigant } \\
\left(\mu \mathrm{g} / \mathrm{cm}^{3}\right)\end{array}$} & D. farinae & 36.50 & $36.44-36.55$ & 1.00 \\
\hline & & D. pteronyssinus & 34.23 & $34.18-34.29$ & 1.00 \\
\hline & & T. putrescentiae & 30.31 & $30.22-30.39$ & 1.00 \\
\hline & \multirow{3}{*}{$\begin{array}{l}\text { Contact } \\
\left(\mu \mathrm{g} / \mathrm{cm}^{2}\right)\end{array}$} & D. farinae & 19.64 & $19.63-19.66$ & 1.00 \\
\hline & & D. pteronyssinus & 14.12 & $14.11-14.13$ & 1.00 \\
\hline & & T. putrescentiae & 14.15 & $14.02-14.26$ & 1.00 \\
\hline
\end{tabular}

${ }^{\mathrm{a}}$ Exposed for $24 \mathrm{~h}$.

${ }^{\mathrm{b}} \mathrm{RT}$, Relative toxicity $=\mathrm{LD}_{50}$ value of $\mathrm{DEET} / \mathrm{LD}_{50}$ value of each compound.

and T. putrescentiae, respectively (Table 2), indicating that $D$. farinae is more susceptible to $L$. japonicum oil than $D$. pteronyssinus and $T$. putrescentiae, regardless of the bioassays. The acaricidal potential of $L$. japonicum oil depends on the bioassay conditions and mite species (Oh et al., 2012). Moreover, the acaricidal activities of $L$. japonicum oil against three acaridae and pyroglyphid mites were attributed to borneol and $\beta$-caryophyllene. The acaricidal activities of borneol and $\beta$-caryophyllene against three acaridae and pyroglyphid mites have been reported previously (Lee et al., 2010; Oh et al., 2014). Nevertheless, this study is the first report on the acaricidal effects of $L$. japonicum oil against three acaridae and pyroglyphid mites. In conclusion, our study showed that the essential oil of L. japonicum leaves may be useful to develop an ecofriendly agent for managing three acaridae and pyroglyphid mites.

Acknowledgments This research was carried out with the support of Cooperative Research Program for Agriculture Science \& Technology Development (Project title: Development of integrated pest management techniques using natural products in the grain storage, Project No: PJ01004502), Rural Development Administration, Republic of Korea.

\section{References}

Adams RP (2007) Identification of essential oil components by gas chromatography/mass spectrometry. Allured Publ. Corp.: Carol Stream, USA.

Arlian LG (1989) Biology and ecology of house dust mite, Dermatophagoides spp. and Euroglyphus spp. Immunol. Allergy Clin 9, 33956.

Azima LH, Siti HA, Ho ZM, Suhaili ZA, and Maizatul HO (2011) Acaricidal activity of Cymbopogon citratus and Azadirachta indica against house dust mites. Asian Pac J Trop Biomed 1, 365-69.

Doh ES (2010) Antibacterial Activity of Medicinal Plant Extracts to $S$. aureus KCCM12256 and $V$. parahaemolyticus KCCM11965. J East Asian Soc Dietary Life 20, 881-7.
Hendriks MMWB, Juarez LC, Bont DD, and Hall RD (2005) Preprocessing and exploratory analysis of chromatographic profiles of plant extracts. Anal Chim Acta 545, 53-64.

Jeon JH and Lee HS (2011) Acaricidal activity of Tabebuia impetiginosa bark-derived constituent against domestic and spider mites (Arachnida: Acari). J Korean Soc Appl Biol Chem 54, 551-7.

Jeon JH, Yang JY, Chung NH, and Lee HS (2012) Contact and fumigant toxicities of 3-methylphenol isolated from Ostericum koreanum and its derivatives against house dust mites. J Agric Food Chem 60, 12349-54.

Lee CH, Kim HW, and Lee HS (2009) Acaricidal properties of piperazine and its derivatives against house-dust and stored-food mites. Pest Manag Sci 65, 704-10.

Lee CH, Lee SG, and Lee HS (2010) Acaricidal effects of Thymus vulgaris leaf-derived materials and monoterpene alcohols against Dermatophagoides spp. J Korean Soc Appl Biol Chem 53, 170-4.

Lim SS, Lee YS, Kim HM, Ahn YH, Shin KH, and Lee SH (2008) GC/MS analysis of volatile constituents from broad-leaved indeciduous trees. Korean J Plant Res 21, 237-48.

Oh MS, Yang JY, and Lee HS (2012) Acaricidal toxicity of 2'-hydroxy-4'methylacetophenone isolated from Angelica koreana roots and structureactivity relationships of its derivatives. J Agric Food Chem 60 , 3606-11.

Oh MS, Yang JY, Kim MG, and Lee HS (2014) Acaricidal activities of $\beta$ caryophyllene oxide and structural analogues derived from Psidium cattleianum oil against house dust mites. Pest Manag Sci 70, 757-62.

Papoti VT, Pegklidou K, Perifantsi E, Nenadis N, Demopoulos VJ, and Tsimidou MZ (2011) Antioxidant and aldose reductase inhibition activity of Ligustrum japonicum and Olea europaea L. leaf extracts. Eur J Lipid Sci Technol 113, 876-85.

SAS Institute (1990) SAS/STAT User's Guide, version 8; SAS Institute: USA.

Yang JY, Cho KS, Chung NH, Kim CH, Suh JW, and Lee HS (2013) Constituents of volatile compounds derived from Melaleuca alternifolia leaf oil and acaricidal toxicities against house dust mites. $J$ Korean Soc Appl Biol Chem 56, 91-4.

Yang JY, Kim MG, Park JH, Hong ST, and Lee HS (2014) Evaluation of benzaldehyde derivatives from Morinda officinalis as anti-mite agents with dual function as acaricide and mite indicator. Sci Rep 4, doi: $10.1038 /$ srep07149.

Yang JY and Lee HS (2012) Acaricidal activities of the active component of Lycopus lucidus oil and its derivatives against house dust and stored food mites (Arachnida: Acari). Pest Manag Sci 68, 564-72. 